\title{
Pulmonary aspergillosis: A review and a description of three new cases
}

\author{
JAMES N. MACART NEY \\ From the Walsall Chest Clinic
}

Aspergillosis, a comparatively rare disease in man though a common one in birds, is caused by the aspergillus, a genus of minute fungi which, in common with other fungi, lacks chlorophyll. It is either parasitic or saprophytic and has a particular affinity for decaying vegetable matter. Included among its species are Aspergillus fumigatus, $A$. niger, $A$. clavatus, $A$. nidulans, $A$. flavus, and $A$. versicolor, of which $A$. fumigatus is regarded as the most important, and only occasionally have other species been mentioned in connexion with human pulmonary infection (Montes, 1963).

Bennett (1844) was the first to describe a case of fungal invasion of the lungs. The patient suffered from phthisis, but doubt exists as to whether the fungus was an aspergillus. The first case of pulmonary aspergillosis was reported by Sluyter (1847) in a woman dying from a chest illness who had a fungal mass in a lung cavity. The fungus, originally reported as a mucor, was later recognized as an aspergillus.

A series of cases of pulmonary aspergillosis were recorded about this time (Friedreich, 1856 ; von Dusch and Pagenstecher, 1857 ; Cohnheim, 1865 ; Virchow, 1856). The latter described in detail four patients with dysentery, pneumonia, emphysema, and gastric carcinoma, in whom the role of the aspergillus was regarded as secondary.

The first description of an allergic type of aspergillosis was in 1887, by Popoff. A woman of 21 years had symptoms of bronchial asthma, and her sputum was negative for tuberculosis but contained many bronchial casts made up of the mycelium and spores of $\boldsymbol{A}$. fumigatus.

The French contributions to the problem of aspergillosis have been many, especially in the late nineteenth century (Rénon, 1893, 1897 ; Dieulafoy, Chantemesse, and Widal, 1890 ; Dévé, 1938 ; and Monod, Pesle, and Labeguerie, 1952). Additional significant progress in aetiology and classification has come from Hinson, Moon, and Plummer (1952) and Pepys, Riddell, Citron, Clayton, and
Short (1959), but many facets of the disease are still unexplained.

The following case histories concern three patients in whom aspergillosis was confirmed histologically.

\section{CASE REPORTS}

CASE 1 (W.W.) A miner, aged 52 years at the time of admission in 1956, had been unfit for work since 1942. A chest radiograph in 1941 (Fig. 1) had suggested cystic bullae in the left upper lobe. After admission to hospital in 1943 because of a perforated gastric ulcer, pulmonary tuberculosis of the left apex was suspected, and, although the sputum was negative, he was transferred to a sanatorium for one month. Serial radiographs from 1945 (Figs. 2-7) revealed a slowly enlarging, solid mass, lying within a thickwalled cavity in the left upper lobe. Beginnning in 1947 , haemoptysis of varying degree persisted intermittently. The patient was admitted to hospital in 1956 with a diagnosis of aspergilloma and had additional gross bronchiectasis in the left lower lobe. At bronchoscopy a generally inflamed mucosa was seen but no stenosis of the left upper lobe bronchus. Bronchial washings were cultured for fungi and tubercle bacilli, but only Candida albicans was isolated. Sputum examinations were repeatedly negative for fungi. A blood count showed a haemoglobin of $80 \%(11.8 \mathrm{~g} . / 100 \mathrm{ml}$.) ; E.S.R. $49 \mathrm{~mm}$. fall in one hour ; W.B.C. $9,800 /$ c.mm. ; polymorphs $71 \%$; lymphocytes $25 \%$; monocytes $3 \%$; and eosinophils $1 \%$.

Because of inadequate respiratory reserve and bronchiectasis, surgery was considered inadvisable. After discharge the patient survived until 1958 when he developed cor pulmonale due to bronchiectasis and died. At necropsy two adjacent mycetomata were found in the left upper lobe (Fig. 8). The larger of the two consisted of a brownish, putty-like, mycelial mass, lying loose within a thick-walled cavity. Culture after 48 hours at $37^{\circ} \mathrm{C}$. produced a pure growth of $A$. fumigatus.

CASE 2 (B.M.C.) A clerk aged 22 years was first seen at the chest clinic on 25 May 1955. Six days earlier he had had an haemoptysis which had persisted. 'The 


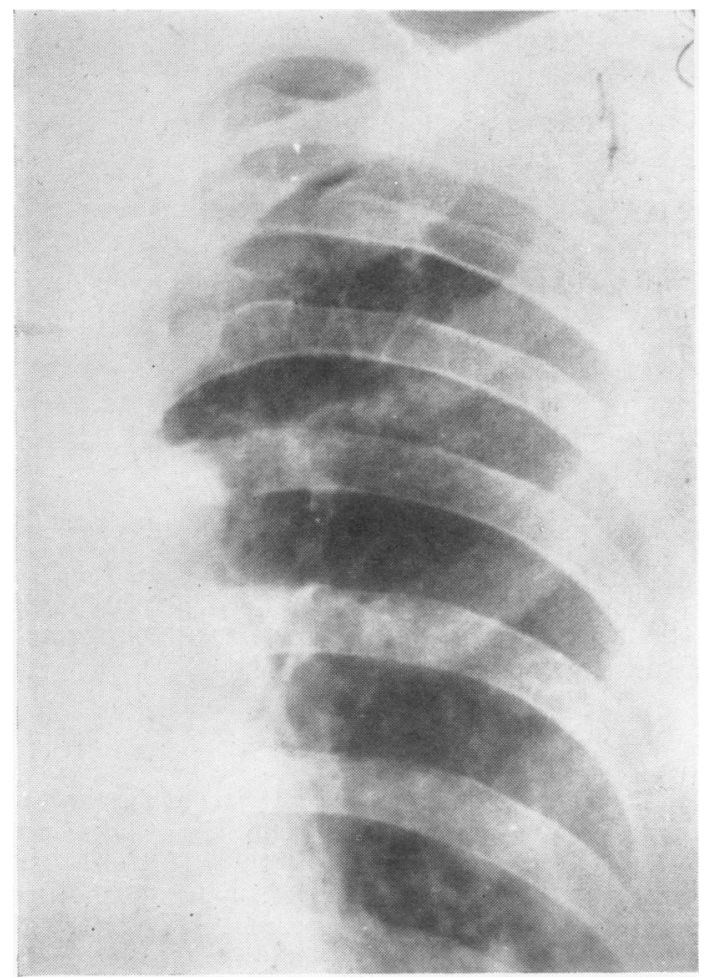

FIG. 1

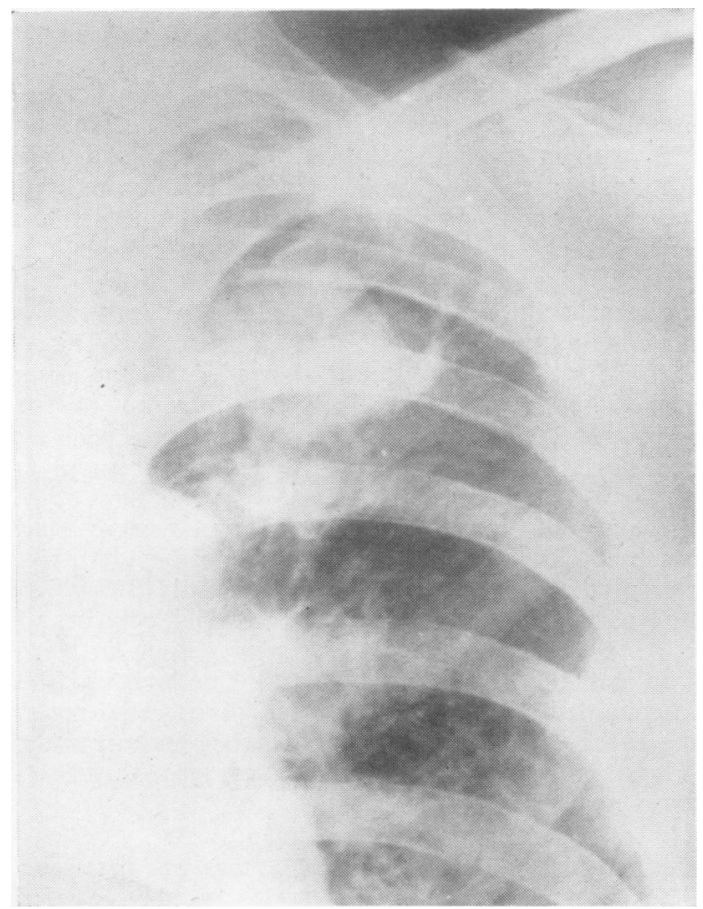

FIG. 3

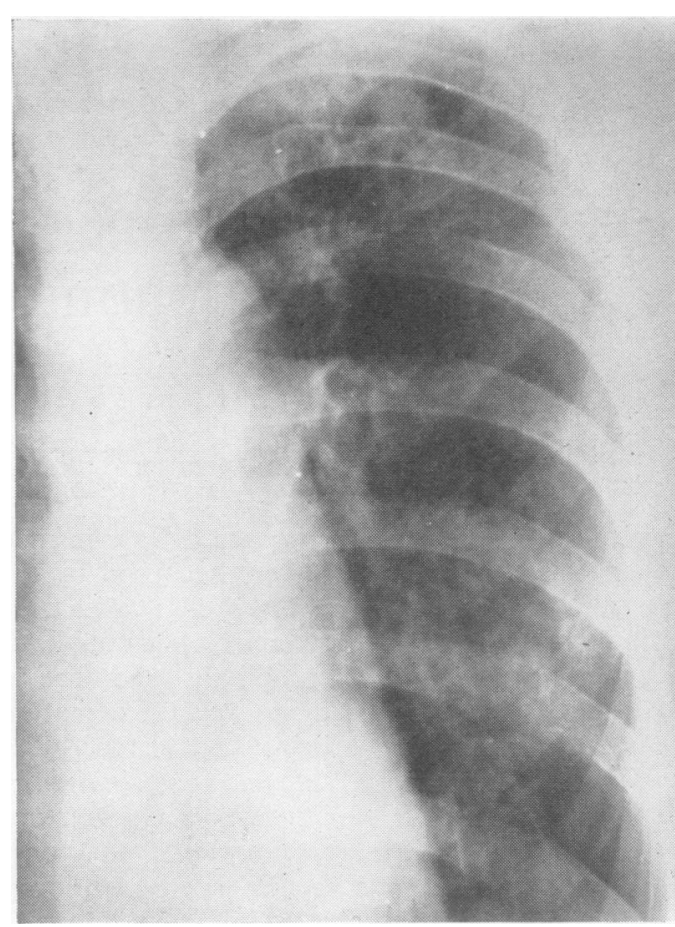

FIG. 2

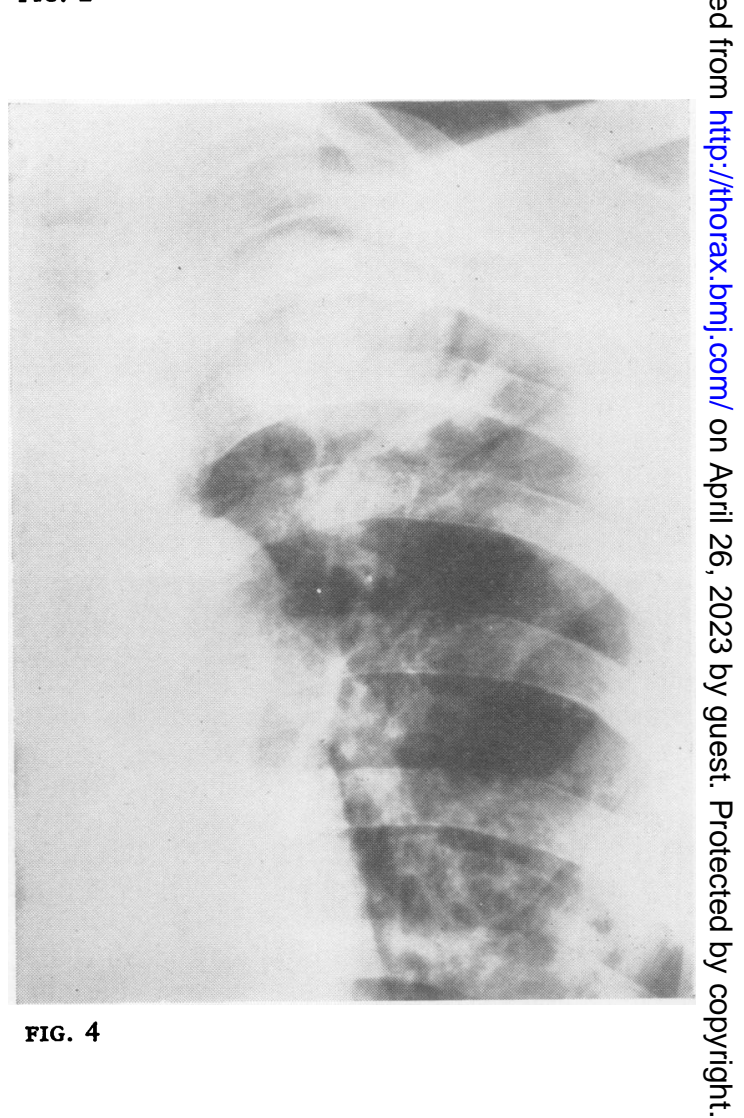




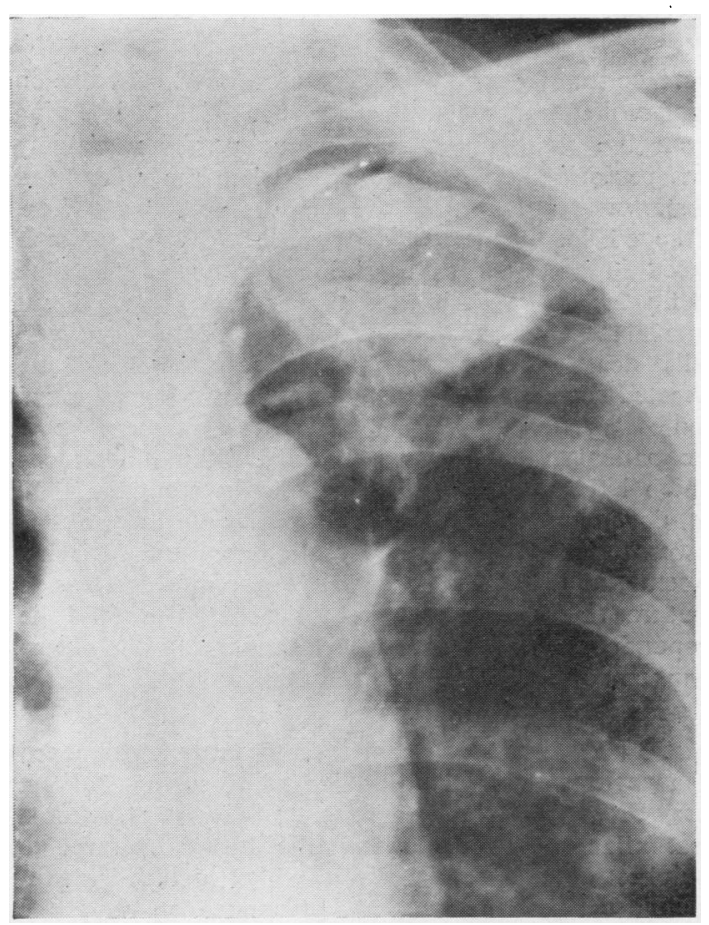

FIG. 5

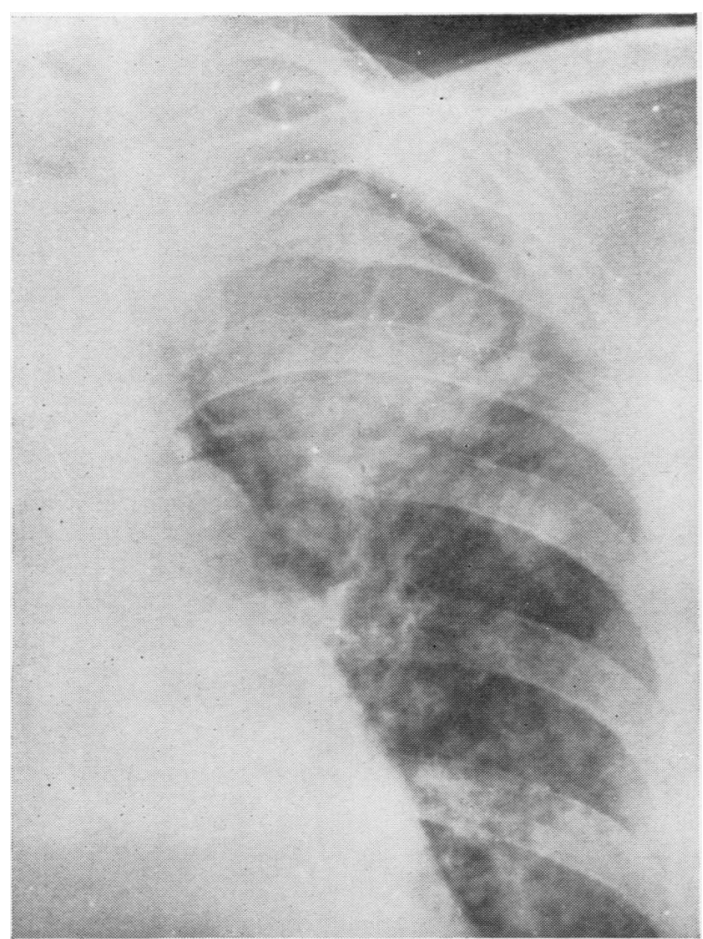

FIG. 7

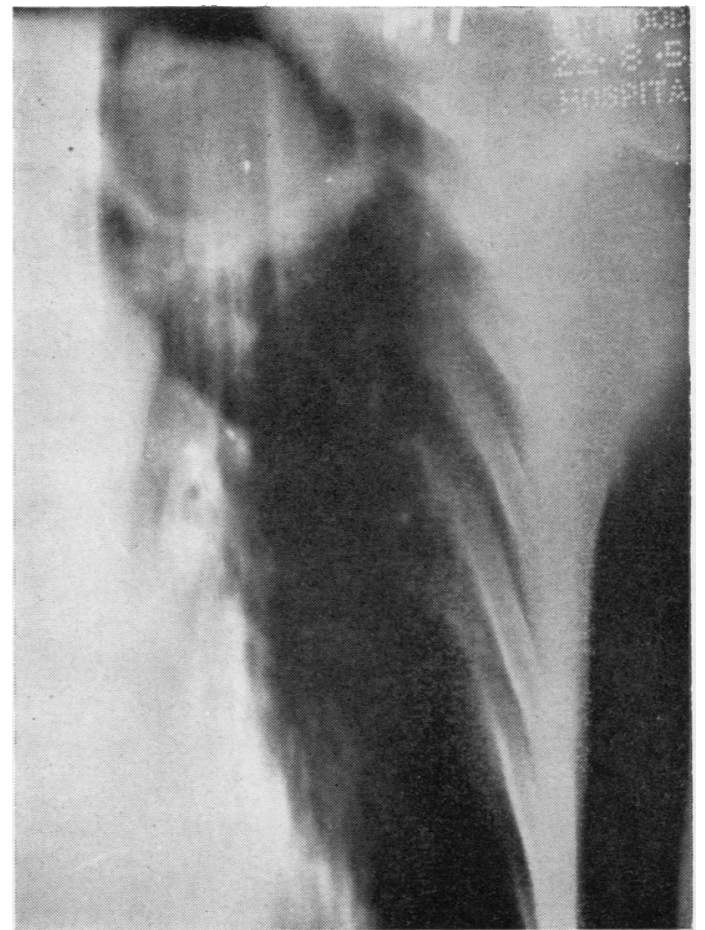

FIG. 6

FIGS. 1-7. Radiographs covering the period 1941 to 1958 and showing the gradual formation of a mycetoma.

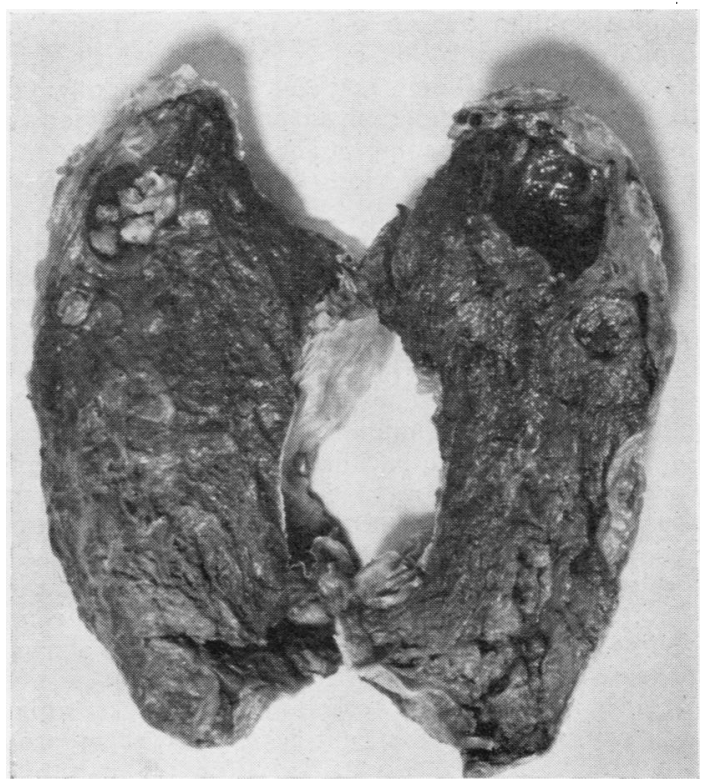

FIG. 8. Necropsy specimen showing two mycetomata. The smaller of the two is situated immediately below the large apical cavity. 


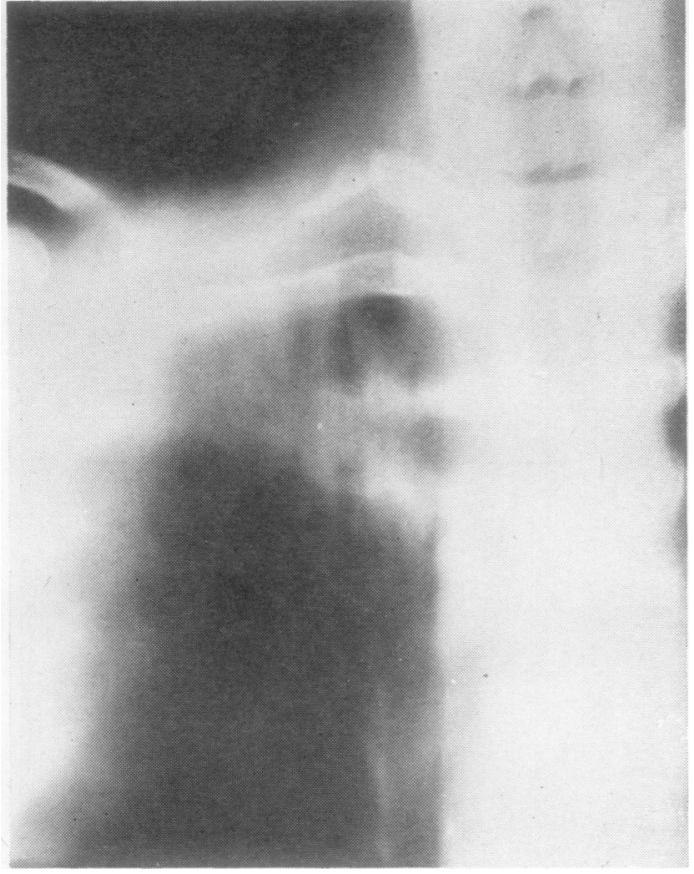

FIG. 9. Tomogram showing a mycetoma in the right upper lobe.

patient had been a known asthmatic since the age of 2 years and had a chronic, productive cough with purulent sputum but no plugs. He was admitted to hospital for investigation on $26 \mathrm{May}$, at which time physical examination revealed no abnormality, although a chest radiograph taken a week previously showed pleural thickening at the right apex. A mass radiograph taken the previous year had been reported as normal.

A blood count on 27 May was as follows: Haemoglobin $90 \%(13.4$ g. $/ 100 \mathrm{ml}$.) ; E.S.R. $24 \mathrm{~mm}$. fall in one hour; W.B.C. $4,600 /$ c.mm.; polymorphs $59 \%$; lymphocytes $38 \%$; monocytes $2 \%$; and eosinophils $1 \%$.

The blood pressure and urine were normal, and on examination of the sputum numerous pus cells were found but no tubercle bacilli. Sputum culture showed a mixed growth of normal flora. Subsequent sputum examinations were repeatedly negative, with the exception of one occasion when gastric lavage produced an acid and alcohol-fast bacillus on direct smear examination. However, the eventual culture was negative. A tomogram taken on 31 August is shown in Figure 9.

Treatment Originally chloramphenicol, $250 \mathrm{mg}$. six-hourly, was given for eight days, followed by procaine penicillin, 300,000 units daily, for five days, but without any improvement symptomatically or radiologically. Streptomycin and isoniazid were begun, together with potassium iodide and stramonium, and were continued until October 1955. Bronchoscopy on $\overrightarrow{\vec{\omega}}$ 25 October confirmed the presence of blood oozing 0 from the right upper lobe bronchus. Thoracotomy $\frac{\bar{\sigma}}{\sigma}$ was performed on 1 November, when the apical and $\overline{\bar{c}}$ posterior segments of the right upper lobe were $\bar{\Phi}$ removed. Post-operatively, some difficulty was experi- $\varrho$ enced in getting the remaining portion of the lung to fill the space. A limited thoracoplasty carried out $\vec{\circ}$ on 17 November, with a partial decortication, successfully dealt with this problem. Examination of the $\vec{\omega}$ resected specimen showed the presence of a mycetoma, and $\boldsymbol{A}$. fumigatus was isolated. In subsequent years $\overrightarrow{\mathcal{2}}$ the patient has continued to have asthmatic attacks which have interfered with his employment. In $1957 \overrightarrow{0}$ he developed a transient consolidation in the left $\rightarrow$ lower lobe, accompanied by slight sputum staining, $\infty$ pyrexia, and wheezing but no eosinophilia. Successive sputum tests were negative for aspergillus, and he responded satisfactorily to treatment with chlor- amphenicol and potassium iodide.

CASE 3 (W.F.) This patient aged 58 years had worked $\vec{\varphi}$ at a variety of occupations, including spring making, $\varnothing$ lorry driving, and coal mining. In May 1959, after a post-influenzal bronchopneumonia, he was referred to the chest clinic. His symptoms, which included a productive cough, wheezing, and dyspnoea on moderate $\overline{0}$ exertion, dated back to childhood but had recently

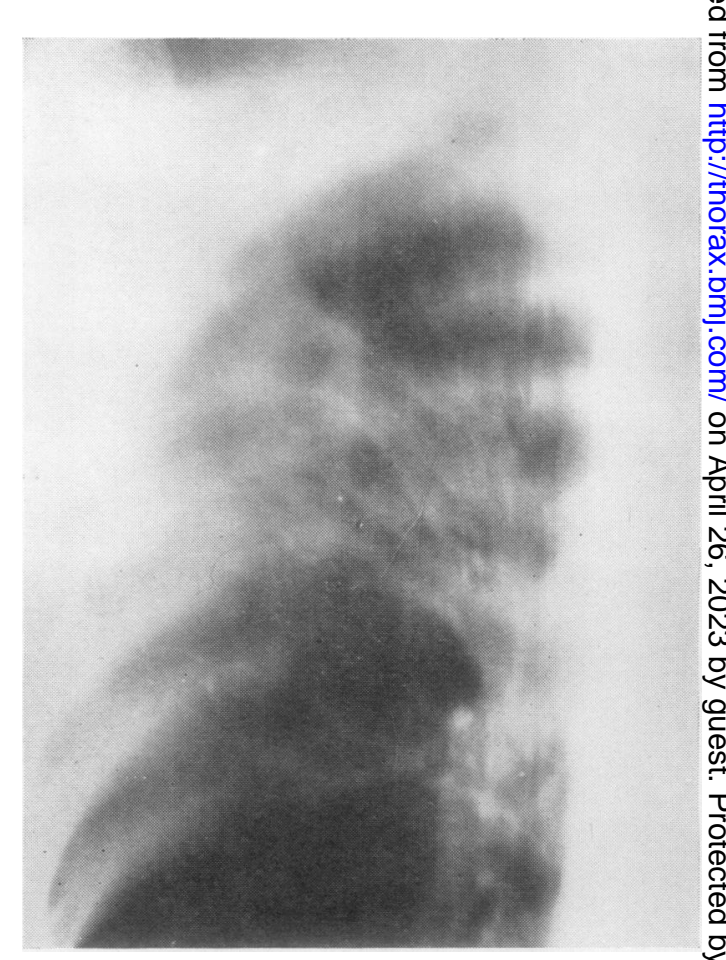

FIG. 10. Radiograph showing cavitation in the right upper lobe. 
become more marked. The sputum was yellowish but never contained blood or plugs. He smoked 15 cigarettes daily. A localized opacity, present in the right upper lobe near the periphery in May, had cavitated by July (Fig. 10).

A blood count was as follows: Haemoglobin $65 \%$ (9.8 g./100 ml.) ; W.B.C. 6,200/c.mm. ; film normal apart from hypochromic R.B.C.s with slight anisocytosis ; E.S.R. $27 \mathrm{~mm}$. fall in one hour.

Sputum examinations revealed no tubercle bacilli.

In September, despite the fact that the sputum was negative, P.A.S. and isoniazid were prescribed pending his admission for thoracotomy, and on 19 October 1959, apical and posterior segments of the right upper lobe were resected, numerous soft pleural adhesions being encountered at operation. The pathological report on the resected specimen was as follows: 'Collapsed lung, showing extensive infiltration and numerous mycotic foci, probably $A$. fumigatus. No yeasts or spores'.

Convalescence after surgery was uneventful, and for two months nystatin tablets were given. Follow-up has been satisfactory but he still suffers from asthma. Repeated sputum examinations have failed to reveal the presence of fungi or eosinophils.

\section{COMMENT}

The natural onset and evolution of an aspergilloma that has been left undisturbed by drugs or surgery has not so far been described. The nearest approach to such a description is Neilson's (1959) account of a fungal infection of a pre-existing lung cyst in a woman who had been irradiated because of a breast carcinoma. Surgical resection of the cyst was necessary, however, and evolution of the fungus was terminated. Case 1, therefore, is of particular interest, as radiographs ranging over a 17-year period clearly trace the fungal changes which ensued. Surgery was not considered advisable for this patient because of poor respiratory reserve caused by bronchiectasis.

The earliest chest film in December 1941 (Fig. 1), while strongly suggesting cystic changes in the left upper lobe, also revealed a small discrete opacity, $0.5 \mathrm{~cm}$. in diameter, opposite the fourth left interspace posteriorly. The slight mediastinal shift to the left was caused by gross bronchiectasis of the left lower lobe, and this finding was subsequently confirmed by bronchography. Four years later in 1945 (Fig. 2) the nodule in the left upper lobe measured $1.5 \mathrm{~cm}$. By 1950 , however, a definite mycetoma had developed consisting of a dense central mass, $4 \times 2.5 \mathrm{~cm}$., within a thick-walled cavity, $5.5 \times 5 \mathrm{~cm}$., and capped by an air halo (Fig. 3). Four years later in 1954 (Fig. 4) the fungal mass had continued to enlarge, measuring $5.5 \times 4 \mathrm{~cm}$., and further slight increases were noted in the following years (Figs. 5 and 6). Eight months before death a definite enlargement of the cavity $(7 \times 6.5 \mathrm{~cm}$.) and of the central mass $(6.5 \times 6 \mathrm{~cm}$.) was noted (Fig. 7). In addition, a new focus had appeared adjacent to the lower border of the cyst. From 1950 onwards the mycetoma increased, both in size and density, while over the same period the air halo was consistently present. The nodule, first seen in 1941, probably represents a fungal nidus which, establishing its hold on a pre-existing air cyst, took nine years to reach the maturity of a mycetoma.

Case 2 displays many of the usual features of a mycetoma, including repeated haemoptyses. The long history of asthma present in cases 2 and 3 is uncommon in association with a myectoma but may have been a significant factor. In all three cases pulmonary tuberculosis was suspected, and although in case 1 a correct diagnosis was eventually established, in the others it was made only after histological examination of the resected specimens.

\section{DISCUSSION}

Only rarely have cases of primary aspergillosis been described, where the fungus has established itself definitely as the only disease (Schneider, 1930 ; Hunt, Broders, Stinson, and Carabasi, 1961 ; Montes, 1963). Orie, de Vries, and Kikstra (1960), finding pre-existent disease so frequently in a series of 51 cases, assumed that secondary fungal involvement is the most common, if not the only form of aspergillosis.

Saprophytism probably explains cases associated with bronchial cysts (Hemphill, 1946; Gerstl, Weidman, and Newmann, 1948 ; Corpe and Cope, 1956), bronchiectasis (Boyce, 1893 ; Barlow, 1954; Bruce, 1957), pneumoconiosis (Heppleston and Gloyne, 1949), tuberculosis (Barlow, 1954 ; Kelmenson, 1959 ; Peer, 1960), cardiac disease (Zimmerman, 1950), mastoiditis (Stuart and Blank, 1955), carcinoma (Sochocky, 1959), asbestosis (Hinson et al., 1952), endocarditis (Welsh and Buchness, 1955), pneumonia (Hertzog, Smith, and Goblin, 1949 ; Ross, 1951 ; Abbott, Fernando, Gurling, and Meade, 1952; Darke, Warwick, and Whitehead, 1957 ; Toigo, 1960), histoplasmosis (Procknow and Loewen, 1960), the orbit (Wright, 1927), sarcoidosis (Pepys et al., 1959), and lung abscess (Wheaton, 1890 ; Yesner and Hurwitz, 1950 ; Stevenson and Reid, 1957).

Hinson et al. (1952) classified aspergillosis as allergic, saprophytic, and septicaemic. The allergic form is associated with recurrent pyrexia, typical brown sputum plugs, the presence of $A$. fumigatus 
in the sputum, blood eosinophilia, transient lung infiltrates, and asthma. Bronchoscopy often shows a polypoid mass causing bronchial obstruction of the affected segment. They explained these findings as allergic manifestations after sensitization to the fungus. In two of their three cases saccular bronchiectasis was present, but whether it preceded or followed the bronchial obstruction could not be determined. Discussion concerning the role of bronchiectasis in aspergillosis originated with Dévé (1938) and has never been solved. The mycetoma or solid fungal mass is usually regarded as a saprophytic manifestation of a fungus growing in a pre-formed cyst, but in France there has always been support for the theory of a fungal ball growing within the lumen of a bronchus and thereby forming its own cyst.

In the pyaemic or septicaemic variety of aspergillosis, multiple abscesses affect all parts of the body, constituting the most serious form and affecting mainly children.

OCCUPATION Between 1958 and 1961, of a total of 980 deaths among birds at the London Zoo, $4 \%$ were due to aspergillosis (Fiennes, 1962). This susceptibility of birds to fungal infection has been known for over a century (Virchow, 1856), and has frequently been reported. It is hardly surprising that a tendency exists to explain human aspergillosis almost as an occupational disease among persons in close contact with birds, grain, flour, and agriculture (Conant, Smith, Baker, Callaway, and Martin, 1954 ; Riddell and Clayton, 1958; Spencer, 1962). Legal support for this view was obtained in 1942 (Coe, 1945), when a middle-aged stockyard worker, whose occupation for 20 years had exposed him to hay, grain, corn, and straw, and whose sputum contained $A$. fumigatus, was awarded compensation for chronic chest symptoms. The fact that this case is solitary in the world literature suggests that aspergillosis and occupation are not closely linked.

Few papers or textbooks dealing with aspergillosis omit to mention its close association with agriculture, bird-feeding (especially of pigeons), milling, fur cleaning, and wig making. As this view stems almost entirely from research carried on between 1890 and 1897 in Paris and appears to be generally accepted without question to-day, it is worth while considering the evidence anew. The gaveurs de pigeons and the peigneurs de cheveux (pigeon crammers and wig-makers) are the two occupations on which the original findings were based. The wig-makers, using rye-flour to degrease hair, worked continually in an atmosphere of dust. The work of the pigeon crammers in Paris and its environs declined towards the end of the nineteenth century, and by 1895 the number of persons so employed was small. A pigeon crammer, having mixed equal parts of water, millet, and vetch in a tub and then filled his mouth with the mixture, would take each pigeon in turn by the wings with one hand, open the beak with the other and forcibly feed his charge, taking on an average one to two seconds per pigeon. Some workers in a day would average 4,000 to 6,000 pigeons.

It was in August 1890 at the International Congress in Berlin that Dieulafoy et al. first described three pigeon crammers with chronic chest symptoms, which they attributed to aspergillosis. The progress of the disease resembled that of chronic phthisis, with dyspnoea, cough, purulent sputum, repeated small haemoptyses, and pleurisy. The sputum microscopically was negative for tubercle bacilli but contained $A$. fumigatus. The authors suggested that grain used for the pigeons and known to be heavily contaminated with the fungus caused the disease which they named pseudo tuberculose mycosique. Presumably, the three patients never came to necropsy, as no postmortem findings were given. Rénon, however, examined one of these men six years later, and, finding him in reasonable health with sputum that contained neither fungi nor tubercle bacilli, concluded that he was cured. A somewhat similar case was described in 1894 by Gaucher and Sergent.

Rénon, pursuing his interest in pulmonary aspergillosis, devoted his thesis in January 1893 in Paris to this subject, describing two patients, both pigeon crammers, with symptoms similar to those described by Dieulafoy et al. The first man had an additional complication in the form of an anal fistula, but his sputum at that time, although containing $A$. fumigatus, was negative for tubercle bacilli. A few years later, in his book Etude sur l'Aspergillose, Rénon (1897), reporting on his follow-up of this patient, mentioned that numerous tubercle bacilli had appeared eventually in the sputum, while the following year he attributed the disappearance of $\boldsymbol{A}$. fumigatus and tubercle bacilli from the sputum to healing and fibrosis.

His second patient, also a pigeon crammer with chronic chest symptoms, a skin tuberculide but no haemoptysis, had sputum containing tubercle bacilli and $\boldsymbol{A}$. fumigatus. He died in hospital in 1895 , and the post-mortem findings were reported by Rénon (1897). Although the lungs were considerably fibrosed, some caseous foci were present, but no aspergilli or tubercle bacilli could be discovered histologically. It is worth noting that this case is the only one in the series 
in which a necropsy was performed. In Rénon's view, while the fungus was responsible for the secondary invasion by tuberculosis, it tended to ensure that the latter progressed slowly, with marked fibrosis.

Rénon's only other cases concern a family, father, mother, and 16-year-old son, who were engaged in wig-making. The son had a chronic tracheitis but no evidence of aspergilli or tubercle bacilli in the sputum. Both parents had chronic coughs with haemoptysis, and their sputum contained $A$. fumigatus but no tubercle bacilli. The father had clinical signs of a marked pulmonary fibrosis.

The only indisputable fact emerging from all these reports is that the patients were engaged in occupations which, by their nature, exposed them to a high concentration of fungal contamination. Riddell and Clayton (1958) and Pepys et al. (1959) have shown that approximately $7 \%$ of patients suffering from a wide variety of chest conditions harbour $\boldsymbol{A}$. fumigatus in their sputum, and Rénon (1897), investigating sputum and nasal secretions in 56 persons, many of whom were healthy, had found the fungus in seven instances. Therefore the presence of $A$. fumigatus need not imply a pathogenic role.

If the incidence of pulmonary aspergillosis were linked to atmospheric fungal pollution, one would expect to find a high proportion of cases in industries where such conditions exist, but this theory is not supported by experience. For example, bagasse shredding by machines produces room dust containing 240 million fungal spores per gramme. Mentioning this fact, Hunter and Perry (1946) also reported that the sputum from four men who operated the shredder contained numerous species of fungi including aspergillus. They regarded these fungal elements as the result of recent dust inhalation and could find no evidence of survival of the fungi in the lungs after the men had been removed from exposure to the atmosphere of the shredding room. In one of the men who died, only chronic bronchiolitis and bronchiectasis was found, but no evidence of aspergillosis. Stallybrass' (1961) study of atmospheric pollution by aspergillus spores in a large animal-provender mill, in which various grains were unloaded, stored, and processed, tends to confirm this view. The catch rate of spores in the normal working atmosphere of the mill was 30 times higher than appeared in the urban atmosphere, and of all the grains handled, maize was the most highly contaminated. Compensation for disease or injury arising out of work was sought by a total of 31 employees between 1956 and
1959, but none was claiming for this disease, and between 1951 and 1959 not a single case of pulmonary aspergillosis was reported. Stallybrass concluded that workers in such industries suffer no additional risk of contracting aspergillosis. Dünner, Hardy, Nakielny, Robinson, and Smart (1958), reporting on necropsy findings in five men out of a total of 31 employed in handling grain and flour, found no evidence of pulmonary aspergillosis.

Taking these facts into consideration, the presence of $\boldsymbol{A}$. fumigatus in the sputum of pigeon crammers and wig-makers is hardly surprising and not diagnostic of a pathological fungus infection in the lungs. Further, when one appreciates that the two patients on whom Rénon based his main argument were both suffering from pulmonary tuberculosis, additional doubts arise as to whether in fact there was any reliable evidence of pulmonary aspergillosis. Certainly chronic phthisis could explain the symptoms in all the cases, and in addition these patients were engaged in highly unhygienic occupations in an era when tuberculosis was rife. It is worth while noting that in the single instance where a necropsy was performed, the histology, although excluding aspergillosis, was extremely suggestive of tuberculosis. Whilst acknowledging the valuable and exacting studies in mycology conducted by Rénon and his co-workers, it cannot be accepted that there is any convincing evidence to date connecting pulmonary aspergillosis with certain occupations, notably those concerned with birds, grain, and their associated trades.

MYCology It is unwise to place too much importance on the presence or absence of the fungus. Isolation of $\boldsymbol{A}$. fumigatus from the sputum does not carry the same significance as a single culture of a known, pathogenic fungus, such as Histoplasma capsulatum (Chick, 1962). Even when the fungus has been clearly demonstrated by frequent sputum cultures, it may still be impossible to see it microscopically in the sputum. Some aspergillomata have no permanent bronchial connexions, and therefore sputum cultures may be negative (Orie et al., 1960). Probably case 1 was of this type, and even suction applied to the left upper lobe orifice produced a negative aspirate.

Saliba, Pacini, and Beatty (1961) successfully demonstrated that, by inserting a needle into an aspergilloma, using local anaesthetic, material can be aspirated for culture. It is advisable to collect sputum specimens in sterile glass containers, incubating at $37^{\circ} \mathrm{C}$. on Sabouraud's medium or on 
blood agar, spread with 1 in 1,000 streptomycin. $A$. fumigatus, if present, will usually appear within 48 hours, but it is advisable to keep plates up to seven days. Sporing cultures are typically smoky green in colour and show on microscopic examination flask-shaped vesicles with a single row of phialides over the upper two-thirds only. An adequate oxygen tension is essential to the development of sporing elements, but mycelium grows under relatively anaerobic conditions (Cawley, 1947). Patency of bronchial communications, therefore, can decide whether or not spores are present.

Aspergillosis may be confused with other conditions, notably actinomycosis. Weed and Dahlin (1950), in reviewing the literature on actinomycosis, were impressed by the number of reports in which photomicrographs showed wide filaments which, in fact, were probably aspergillus. This point is underlined by a description of a woman aged 48 years with a chronic empyema and multiple fistulae. At operation greyish sulphur bodies were obtained, which were reported by the laboratory as being actinomyces but on culture proved to be $\boldsymbol{A}$. fumigatus. Hughes, Gourley, and Burwell (1956) mention a similar resemblance to the sulphur granules of actinomycosis, produced by $A$. fumigatus forming small clumps of actinomycetoid bodies.

ANTIBIOTICS AND STEROIDS Although the evidence to date is inconclusive, antibiotics and steroids came under early suspicion as agents promoting fungal invasion in man (Hiddlestone, Rosser, and Seal, 1954 ; Darke et al., 1957 ; Torack, 1957). In a case of drug-induced agranulocytosis with secondary aspergillosis, such as that described by Rankin (1953), the responsibility of the drug cannot be questioned. Welsh and Buckness (1955), reporting a case of agranulocytosis treated with antibiotics and steroids, regarded the widespread fungal involvement as a terminal event. Similarly, when Greer and Gemoets (1943) in the pre-antibiotic and steroid era stated that there seemed to be a tendency for pulmonary tuberculosis to develop a more devastating course when associated with the invasion of a parasitic fungus, they may have been describing how fungal colonization tends to select individuals with the grossest pulmonary disease. Streptomycin, which has been used extensively over the past decade, has not been associated with an increase in fungal disease. Nor have surgical resection of tuberculous tissue after prolonged ohemotherapy and the concomitant histological and bacteriological investigations revealed significant fungal intrusion.
Abbott et al. (1952) described a housewife $\stackrel{\overrightarrow{\bar{F}}}{\stackrel{\overrightarrow{3}}{*}}$ admitted in 1951 with a post-influenzal broncho- 0 pneumonia and toxic purpura. She was treated unsuccessfully with penicillin and chloramphenicol $\frac{\rho}{\sigma}$ and died in coma. At necropsy a thin-walled $\stackrel{\mathbb{\complement}}{\varrho}$ cavity, $5 \mathrm{~cm}$. in diameter, was found to be lined क with a densely felted layer of fungal mycelium and $\vec{\circ}$ conidia. Material from the cavity, when cultured, produced $A$. fumigatus, Candida albicans, $\vec{\omega}$ coagulase-negative staphylococci, and haemolytic streptococci. The cause of death was considered $\vec{x}$ to be toxaemia, due to a post-influenzal broncho- $\vec{\oplus}$ pneumonia, complicated by an aspergillus infection arising from the use of antibiotics. The known characteristics of the aspergillus-sapro- $-\mathbb{0}^{-}$ phytic, ubiquitous, with a preference for cavitated을 areas-would explain its appearance in this casewithout invoking the use of antibiotics as anc important factor. A similar case was described a $<$ century ago by Virchow (1856) at a time when $\vec{\oplus}$ antibiotics could not be incriminated.

Although Sidransky and Pearl (1961) and Torack (1957) place considerable stress on pasto treatment with antibiotics and steroids, it is worth noting that all their cases were suffering from serious primary diseases, such as agranulocytosis, $\frac{\mathscr{Q}}{\mathbb{Q}}$

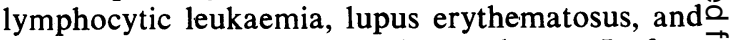
carcinoma of the cervix and oesophagus. In four $\overrightarrow{\vec{o}}$ of these the duration of steroid therapy was only 3 10 days or less, while in a fifth case none was given. Cases coming to necropsy, where evidence? of aspergillosis is discovered, almost invariably have died from serious underlying disease (Orie음 et al., 1960), and the evidence so far suggests that any previous treatment with steroids or antibiotics is coincidental so far as the fungus is concerned.

SYMPTOMS At bronchoscopy in case 2 described earlier, blood was seen issuing from the orifice? of the right upper lobe where the fungal infection was situated. Endeavours to establish the source of bleeding in case 1 were unsuccessful, as he hadN ceased to bleed a few hours before bronchoscopy: The lower lobe was bronchiectatic and must share suspicion. In case 3 there was no history ofw sputum staining, despite the presence of a cavio tated zone in the right upper lobe. Althougho asymptomatic cases have been described, aळ chronic productive cough, accompanied by: repeated intermittent haemoptyses, without obvious deterioration in the patient's general con $\frac{\text { ? }}{\mathbb{D}}$ dition, is often associated with an aspergilloma? Levin (1956), for example, estimated that haem- $\Omega$ optysis occurred in over half the patients, and ing this respect cases 1 and 2 are characteristic. In general, although the pathogenicity of the asper음 
gillus is low, haemoptysis in such cases is usually regarded as directly attributable to the fungus. An endotoxin that causes tissue necrosis has been isolated from the aspergillus and may be responsible for the bleeding.

RADIOLOGICAL CHANGES Frequently, but not invariably, the radiological changes in pulmonary aspergillosis can be non-specific, such as mottling and fibrotic infiltration, confluent nodular infiltrates, clouding, and multiple fleeting shadows. In secondary aspergillosis, the primary condition, such as tuberculosis or neoplasm, may impose its own particular pattern, masking the presence of the fungus. The classical picture of a mycetomadescribed by Monod et al. (1952) as a 'rounded opacity, topped by a clear crescent-is, however, diagnostic. Irregular, calcified densities within the cavities have been described by Villar, Pimentel, and Costa (1962), who also attribute cavity shrinkage to a ball-valve mechanism produced by a mobile intracavitary mass. The central mass, for example, has occasionally been observed to move as the patient changes his position (Hemphill, 1946). A mycetoma is usually solitary but can be multiple, as shown in case 1 , and even bilateral (Saliba et al., 1961).

It is difficult, if not impossible, to distinguish radiologically between pulmonary fibrosis and increased vascularity of lung tissue (Simon, 1962). The unusual cirrus-like markings extending from the hilum to the mycetoma in case 3 (Fig. 10) probably represent a combination of both these processes. In the other two cases similar changes could not be detected, possibly because the mycetomata were localized adjacent to the mediastinum. None of these cases had periostitis of adjacent ribs, such as Bates and Cruickshank (1957) noted in respect of actinomycosis.

ALLERGY In two of the three cases described in this paper, asthmatic symptoms had been present since childhood, and both patients, while showing no 'late' reactions, have vigorous immediate skin reactions to mixed inhalants and fungal allergens (Alternaria, Aspergillus, Gladosporum, Neurospora mucor, and Penicillium). Case 3, when tested for aspergillus precipitins, reacted in a non-specific manner, but case 2 gave a positive reaction. Positive skin reactions to fungal allergens have been noted often but do not necessarily imply actual infection (Conant et al., 1954). Case 1, representing an invasion of a pre-formed cyst, was without asthma, and, as might be expected, did not react to skin tests. In none of the three cases was eosino- philia noted, but case 2 has had at least one infective chest episode since surgery.

It is possible that in the two patients who displayed symptoms of hypersensitivity, their allergy may have been a factor in promoting the formation of a mycetoma. For example, Dunnill (1960), describing areas of cystic bronchiectasis in patients dying of status asthmaticus, frequently found them to have a similar distribution as focal areas of collapse in the upper and lower lobes. Mucosal shedding of great magnitude due to subepithelial oedema occurs in asthma (Naylor, 1962). In addition, sputum and bronchial plugs expectorated by asthmatics are known to contain $A$. fumigatus more frequently than bronchial secretions from patients with other respiratory diseases. In such a complicated situation, an allergic response to inhaled aspergillus spores, as suggested by Hinson et al. (1952), might lead to fungal retention and eventually to the formation of a mycetoma.

Cases of asthma displaying the features associated with allergic pulmonary aspergillosis, namely, transient lung infiltrates, sputum plugs containing $A$. fumigatus, and eosinophilia, have not so far been recognized in the Walsall area, but they do undoubtedly exist. Pepys et al. (1959) consider that the infiltrates are related to an Arthus type of reaction and suggest that there are two types of antibody against aspergillus extracts. The first, a non-precipitating skin-sensitizing antibody, is associated with the skin and bronchial test reactions and is responsible for the rhinitis and asthma. The second, a precipitating antibody, mediates the 'late' Arthus skin reactions and pulmonary eosinophilia.

DRUG THERAPY None of the three cases described here was given antifungal drugs, apart from potassium iodide in case 2 and nystatin postoperatively in case 3 . However, a wide variety of drugs have been used, especially in North America, among which are amphotericin B, nystatin, hydroxystilbamidine, and iodides. The most authoritative statement so far has been the report of the American Thoracic Society Committee on Therapy (1963), which places amphotericin $\mathrm{B}$ as the most valuable drug in aspergillosis, followed by nystatin, hydroxystilbamidine, $\mathrm{X} 5079 \mathrm{C}$, and iodides. Amphotericin B is usually given by intravenous infusion on alternate days, in a dosage rarely exceeding $1.5 \mathrm{mg} . / \mathrm{kg}$. body weight. The total duration of treatment varies from 16 to 36 weeks, but limiting factors are nausea, anorexia, vomiting, fever, chills, anxiety, headache, and thrombophlebitis. Antipyretic and antihistamine drugs, as well as hydrocortisone, are 
useful in combating these side-effects. Renal toxicity is encountered, and, although usually reversible, may be serious. The Committee advised that amphotericin B, because of its disadvantages and despite its high rating as an antifungal agent, should only be used to combat severe or progressive fungal infections. It seems unnecessary to use amphotericin B as a routine measure in simple aspergillomata, even as surgical cover. Reports on its use in allergic aspergillosis are lacking. The original encouraging reports on X5079C (Emmons, 1961), a drug produced from a strain of streptomyces, have unfortunately not been sustained.

SURGERY Once diagnosed, and often when misdiagnosed, the tendency is to resect the mycetoma, and there are few instances where it has been left undisturbed. The aspergillus, especially when it has successfully established itself in a bronchogenic cyst, appear to be invulnerable both to the host and to antifungal agents. The process is irreversible, and, even if the fungus dies, it remains entombed. It is hardly surprising, therefore, that since the first successful resection of a mycetoma was performed in 1943 (Gerstl, Weidman, and Newmann, 1948) the claims of surgery have been pressed as the only effective form of treatment (Pesle and Monod, 1954).

Satisfactory surgical results, as in cases 2 and 3, have been reported on many occasions (Hochberg, Griffin, and Bicunas, 1950 ; Yesner and Hurwitz, 1950 ; Friedman, Mishkin, and Lubliner, 1956 ; Corpe and Cope, 1956; Vellios, Crawford, Gatzimos, and Haynes, 1957), including a case of histoplasmosis with cavitation secondarily infected with A. fumigatus (Procknow and Loewen, 1960). Belcher and Plummer (1960), however, consider resection justifiable only if there is a marked increase in the size of the lesion or frequent troublesome haemoptyses, such as were experienced by case 2 . Finding that no symptomatic improvement followed surgery in allergic aspergillosis and that the fungus persisted in the sputum, they advised against surgical intervention in this type of case. Like other authors, they noted a high incidence of complications accompanying surgery where the aspergillosis was superimposed on primary disease, such as tuberculosis or bronchiectasis. Hiddlestone et al. (1954) and Golebiowski (1958) reported pleural involvement by the aspergillus after resection for tuberculosis in two patients. Such a complication's response to treatment is no more tedious than an empyema due to other organisms. For example, in 1924 Cleland described an aspergillus-infected empyema caused by a gunshot wound, which was successfully treated by partial rib resection, $\overrightarrow{\overrightarrow{\vec{\omega}}}$ 'scraping' of the cavity, and excision.

\section{SUMMARY}

Three cases of aspergillus infection of the lungso are presented, and in one the gradual development of a mycetoma is traced over a 17-year? period. The evolution of the original fungal nidus was shown to be progressive, terminating onlyo with the patient's death.

A marked pulmonary reaction, producing an unusual cirriform radiological appearance, was ${ }^{\circ}$ noted in one of the cases, and in similar circum stances might be of diagnostic importance.

Sputum frequently contains aspergillus if theo person concerned works in an atmosphere con-taminated with the fungal spores, but such peoples show no increased incidence of aspergillosis.

The basis for the theory supporting a close asso $-\overrightarrow{0}$ ciation between pulmonary aspergillosis and birds grain, flour, and allied products as well as occupa: tions, has been re-examined. It is suggested thato no such association exists and that the cases ori ginally described by French workers towards theo end of the nineteenth century were suffering fromp chronic tuberculosis and not aspergillosis. As bird? fancier's disease, pigeon crammer's disease, an $\vec{\delta}$ other similar descriptive terms are misnomers, it $\bar{B}$ is proposed that they should cease to be used.

Aspergillosis of the lungs is essentially secondar? in character. The underlying primary disease especially if serious, plays a dominant role in? establishing the fungus.

Evidence incriminating antibiotics and steroide is unconvincing.

Amphotericin B, despite its toxic side-effectso remains the most valuable drug for the treatment of severe aspergillus infections.

My thanks are due to Mr. S. J. MacHale and Mr. S음 Stephenson for their surgical assistance, and to $\mathrm{Dr}_{\mathrm{N}}$ D. Hewspear and Dr. R. G. F. Parker for the pathoo logical reports.

\section{REFERENCES}

Abbott, J. D., Fernando, H. V. J., Gurling, K., and Meade, B. WE (1952). Pulmonary aspergillosis following post-influenzal bronf chopneumonia treated with antibiotics. Brit. med. J., 1, 523. CS American Thoracic Society Committee on Therapy. (1963). Ameŕ.

Rev. resp. Dis., 87, 784 .
Barlow, D. (1954). Aspergillosis complicating pulmonary tubero culosis. Proc. roy. Soc. Med., 47, 877.

Bates, M., and Cruickshank, G. (1957). Thoracic actinomycosis

Thorax, 12, 99 . pulmonary aspergillosis. Brit. J. Dis. Chest, $54,335$.

Bennett, J. H. (1844). On the parasitic vegetable structures foun growing in living animals. Trans. roy. Soc. Edinb., 15, 277.

Boyce, $R$. (1893). Remarks upon a case of aspergillar pneumonomy cosis. J. Path, Bact., 1, 163, 
Biuce, R. A. (1957). A case of pulmonary aspergillosis. Tubercle (Lond.), 38, 203.

Cawley, E. P. (1947). Aspergillosis and the aspergilli: Report of a unique case of the disease. Arch. intern. Med., 80, 423 .

Chick, E. W. (1962). Pulmonary fungal infections simulating and misdiagnosed as other diseases. Amer. Rev, resp. Dis, $85,702$.

Cleland, J. B. (1924). Aspergillosis of the pleura with sclerotum formation. Med. J. Aust., 1, 634 .

Coe, G. C. (1945). Primary bronchopulmonary aspergillosis, an occupational disease. Ann. intern. Med., 23, 423.

Cohnheim (1865). Zwei Fälle von Mycosis der Lungen. Virchows Arch. Path. Anat., 33, 157.

Conant, N. F., Smith, D. T., Baker, R. D., Callaway, J. L., and Martin, D.S. (1954). Aspergillosis. Manual of Clinical Mycology, 2nd ed., p. 204. Saunders, Philadelphia.

Corpe, R. F., and Cope, J. A. (1956). Bronchogenic cystic disease complicated by unsuspected choleraesuis and aspergillus infestation. Amer. Rev. Tuberc., 74, 92.

Darke, C. S., Warrack, A. J. N., and Whitehead, J. E. M. (1957). Pulmonary aspergillosis-report of a case. Brit. mea. J., 1, 984 .

Dévé, F. (1938). Une nouvelle forme anatomo-radiologique de mycose pulmonaire primitive. Le méga-mycétome intra-bronchectasique. Arch. med.-chir. Appar. resp., 13, 337.

Dieulafoy, G., Chantemesse, A., and Widal, G. F. I. (1890). Une pseudo-tuberculose mycosique. Congrès international de Berlin. Gaz. Hôp. (Paris). 63, 821.

Dünner, L., Hardy, R., Nakieiny, E., Robinson, L. B., and Smart, G. A. (1958). Pneumoconiosis in grain workers, oil and flour millers. Brit. J. Tuberc., 52, 291.

Dunnill, M.S. (1960). The pathology of asthma, with special reference to changes in the bronchial mucosa. J. clin. Path., 13, 27.

Dusch, von, and Pagenstecher, A. (1857). Fall von Pneumonomycosis. Virchows Arch. path. Anat., 11, 561.

Emmons, C. W. (1961). Chemotherapeutic and toxic activity of the antifungal agent $\mathrm{X}-5079 \mathrm{C}$ in experimental mycoses. Amer. Rev. resp. Dis., 84, 507

Fiennes, R. N.T. W. (1962). A penguin health problem. New Scientist, 16, 148 .

Friedman, C., Mishkin, S., and Lubliner, R. (1956). Pulmonary resection for aspergillus abscess of the lung. Dis. Chest, 30, 345 .

Friedreich, N. (1856). Fall von Pneumonomycosis aspergillina. Virchows Arch. path. Anat., 10, 510.

Gaucher, E., and Sergent, E. (1894). Un cas de pseudo-tuberculose aspergillaire simple chez un gaveur de pigeons. Bull. Soc. méd. Hôp. Paris, 3 ser., 11, 512.

Gerstl, B., Weidman, W. H., and Newmann, A. V. (1948). Pulmonary aspergillosis. Report on two cases. Ann. intern. Med., 28, 662.

Golebiowski, A. K. (1958). Pleural aspergillosis following resection for pulmonary tuberculosis. Tubercle, 39,111 .

Greer, A. E., and Gemoets, H. N. (1943). The coexistence of pathogenic fungi in certain chronic pulmonary diseases: with especial reference to pulmonary tuberculosis. Dis. Chest, 9,212 .

Hemphill, R. A. (1946). Mycotic lung infection. Amer. J. Med., $1,708$.

Heppleston, A. G., and Gloyne, S. R. (1949). Pulmonary aspergillosis in coal workers. Thorax, 4, 168 .

Hertzog, A. J., Smith, T. S., and Goblin, M. (1949). Acute pulmonary aspergillosis. Pediatrics, 4, 331.

Hiddlestone, H. J. H., Rosser, T. H. L., and Seal, R. M. E. (1954). Pulmonary aspergillosis. Tubercle (Lond.), 35, 15.

Hinson, K. F. W., Moon, A. J., and Plummer, N. S. (1952). Bronchopulmonary aspergillosis-a review and a report of eight new cases. Thorax, 7,317

Hochberg, L. A., Griffin, E. H., and Bicunas, A. D. (1950). Segmental resection of the lung for aspergillosis, Amer. $J$. Surg. 80,364

Hughes, F. A., Gourlev, R. D., and Burwell, J. R. (1956). Primary pulmonary aspergillosis. Report of an unusual case successfully treated by lobectomy. Ann. Surg., 144, 138

Hunt, W., Broders, A. C., Stinson, J. C., and Carabasi, R. J. (1961) Primary pulmonary aspergillosis, with invasion of the mediastinal contents and lymph nodes. Amer. Rev. resp. Dis., 83, 886.

Hunter, D., and Perry, K. M. A. (1946). Bronchiolitis resulting from the handling of bagasse. Brit. J. industr. Med., 3, 64.

Kelmenson, V. A. (1959). Treatment of pulmonary aspergillosis. Dis. Chest, 36, 442.

Levin, E. J. (1956). Pulmonary intracavitary fungus ball. Radiology, 66, 9 .

Monod, O., Pesle, G. D., and Labeguerie, M. (1952). L'aspergillome bronchectasiant. J. Franc. Méd. Chir. thor., 6, 229.
Montes, M. (1963). Pathologic study of a case of primary pulmonary aspergillosis. Amer. Rev. resp. Dis., 87, 409.

Naylor, B. (1962). The shedding of the mucosa of the bronchial tree in asthma. Thorax, 17, 69 .

Neilson, D. B. (1959). Pulmonary aspergillosis associated with radiation pneumonitis. Scot. med. J., 4, 557.

Orie, N. G. M., de Vries, G. A., and Kikstra, A. (1960). Growth of aspergillus in the human lung: Aspergilloma and aspergillosis. Amer. Rev. resp. Dis., 82, 649.

Peer, E. T. (1960). Case of aspergiliosis treated with amphotericin B. Dis. Chest, 38, 222.

Pepys, J., Riddell, R. W., Citron, K. M., Clayton, Y. M., and Short, E. I. (1959). Clinical and immunologic significance of aspergillus fumigatus in the sputum. Amer. Rev. resp. Dis., 80, 167

Pesle, G. D., and Monod, O. (1954). Bronchiectasis due to aspergilloma. Dis. Chest $25,172$.

Popoff, L. W. (1887). Jber. Fortschr. path. Mikroorg., 3, 316.

Procknow, J. J., and Loewen, D. F. (1960). Pulmonary aspergillosis with cavitation secondary to histoplasmosis. Amer. Rev. resp. Dis., 82, 101.

Rankin, N. E. (1953). Disseminated aspergillosis and moniliasis associated with agranulocytosis and antibiotic therapy. Brit. med. $J, 1,918$.

Rénon, L. (1893). Recherches cliniques et Expérimentales sur la Pseudo-Tuberculose Aspergillaire. Thèse de Paris, No. 89. (1897). Étude sur L'Aspergillose chez les Animaux et chez l'Homme. Masson, Paris.

Riddell, R. W., and Clayton, Y. M. (1958). Pulmonary mycoses occurring in Britain. Brit. J. Tuberc., 52, 34

Ross, C. F. (1951). A case of pulmonary aspergillosis. J. Path. Bact., 63, 409.

Saliba, A., Pacini, L., and Beatty, O. A. (1961). Intracavitary fungus balls in pulmonary aspergillosis. Brit. J. Dis. Chest, 85,65 .

Schneider, L. V. (1930). Primary aspergillosis of the lungs. Amer. Rev. Tuberc., 22, 267.

Sidransky, H., and Pearl, M. A. (1961). Pulmonary fungus infections associated with steroid and antibiotic therapy. Dis. Chest, 39, 630 .

Simon, G. (1962). Principles of Chest $x$-ray Diagnosis, pp. 132-134, 2nd ed. Butterworths, London.

Sluyter, T. (1847). De Vegetalibus Organismi Animalis Parasitis. Diss. Inaug. Berolini, p. 14. Cited by Rénon, 1897.

Sochocky, S. (1959). Infection of pneumonectomy space with aspergillus fumigatus treated by 'Nystatin'. Dis. Chest, 36, 554.

Spencer, H. (1962). Pathology of the Lung, p. 206. Pergamon Press, Oxford.

Stallybrass, F. C. (1961). A study of aspergillus spores in the atmosphere of a modern mill. Brit. J. industr. Med., 18, 41.

Stevenson, J. G., and Reid, J. M. (1957). Bronchopulmonary aspergillosis-report of a case. Brit. med. J., 1, 985.

Stuart, E. A., and Blank, F. (1955). Aspergillosis of the ear-a report of twenty-nine cases. Canad. med. Ass. J., 72, 334.

Toigo, A. (1960). Pulmonary aspergillosis. Amer. Rev. resp. Dis., 81, 392.

Torack, R. M. (1957). Fungus infections associated with antibiotic and steroid therapy. Amer. J. Med., 22, 872

Vellios, F., Crawford, A. S., Gatzimos, C. D., and Haynes, E. (1957) Bronchial aspergillosis occurring as an intracavitary 'fungus ball'. Amer. J. clin. Path., 27, 68.

Villar, T. G., Pimentel, J. C., and Freitas e Costa, M. (1962). The tumour-like forms of aspergillosis of the lung (pulmonary aspergilloma). Thorax, 17, 22.

Virchow, R. (1856). Beiträge zur Lehre von den beim Menschen vorkommenden pflanzlichen Parasiten. Virchows Arch. path. Anat., 9, 557.

Weed, L. A., and Dahlin, D. C. (1950). Bacteriologic examination of tissue removed for biopsy. Amer.J. clin. Path., 20, 116

Welsh, R. A., and Buchness, J. M. (1955). Aspergillus endocarditis, myocarditis and lung abscesses. Ibid., 25, 782 .

Wheaton, S. W. (1890). Case primarily of tubercle, in which a fungus (aspergillus) grew in the bronchi and lung, simulating actinomycosis. Trans. path. Soc. Lond., $41,34$.

Wright, R. E. (1927). Two cases of granuloma invading the orbit due to an aspergillus. Brit. J. Opthal., 11, 545 .

Yesner, R., and Hurwitz, A. (1950). A report of a case of localized bronchopulmonary aspergillosis successfully treated by surgery. J. thorac. Surg., 20, 310.

Zimmerman, L. E. (1950). Candida and aspergillus endocarditis. Arch. Path., 50, 591. 